\title{
Role perceptions of occupational therapists providing support and education for caregivers of persons with dementia.
}

\author{
Susan Toth-Cohen \\ Thomas Jefferson University
}

Follow this and additional works at: https://jdc.jefferson.edu/otfp

Part of the Occupational Therapy Commons

Let us know how access to this document benefits you

\author{
Recommended Citation \\ Toth-Cohen, Susan, "Role perceptions of occupational therapists providing support and \\ education for caregivers of persons with dementia." (2000). Department of Occupational \\ Therapy Faculty Papers. Paper 33. \\ https://jdc.jefferson.edu/otfp/33
}

This Article is brought to you for free and open access by the Jefferson Digital Commons. The Jefferson Digital Commons is a service of Thomas Jefferson University's Center for Teaching and Learning (CTL). The Commons is a showcase for Jefferson books and journals, peer-reviewed scholarly publications, unique historical collections from the University archives, and teaching tools. The Jefferson Digital Commons allows researchers and interested readers anywhere in the world to learn about and keep up to date with Jefferson scholarship. This article has been accepted for inclusion in Department of Occupational Therapy Faculty Papers by an authorized administrator of the Jefferson Digital Commons. For more information, please contact: JeffersonDigitalCommons@jefferson.edu. 


\section{Role Perceptions of}

Occupational Therapists

Providing Support and

Education for Caregivers

of Persons With

Dementia

\author{
Susan Toth-Cohen
}

Key Words: Alzheimer's disease $\bullet$ community occupational therapy $\bullet$ professional practice

Susan Toth-Cohen, PhD, OTR/L, is Assistant Professor, Thomas Jefferson University, Department of Occupational Therapy, 130 South 9th Street, Suite 822, Philadelphia, Pennsylvania 19107; Susan.Toth-Cohen@mail.tju.edu.

This article was accepted for publication September 6, 1999, under the editorship of Editor Emerita, Elaine Viseltear.
Objective. This pilot study explored occupational therapists' perceptions of their roles as interventionists providing education and support for caregivers of persons with dementia. The intervention was provided in caregivers' homes as part of a larger funded study.

Method. Interviews were conducted with four occupational therapists to elicit their reflections on practice and their views on occupational therapy services on the basis of their experiences providing support and education for caregivers in the funded study.

Results. Key themes consisted of the contrasts between the therapists' roles in the study and their customary practices and the professional and personal impact of their role in the study. Their recommendations for occupational therapy services emphasized the need to (a) collaborate with patients, families, and other health care staff members to solve problems; (b) acknowledge others as experts; (c) include family perspectives; and (d) fully address the needs of patients and families in their home environments.

Conclusion. Providing support and education for caregivers in the community can be a major transition for therapists accustomed to practicing in more traditional settings. Additional research is needed to explore the ways in which specific practice contexts influence delivery of occupational therapy services.

Toth-Cohen, S. (2000). Role perceptions of occupational therapists providing support and education for caregivers of persons with dementia. American Journal of Occupational Therapy, 54, 509-515.

A $s$ occupational therapy practice moves away from expert roles in traditional hospital settings toward consultative and educational roles in the community (Devereaux, 1991), occupational therapists must develop skills and knowledge to support their work in community practice (Baum \& Law, 1998; McCall, 1998). Ethnographic principles represent a source of knowledge that can inform and support performance of educational roles in practice. Gitlin, Corcoran, and LeinmillerEckhardt (1995) identified specific ways in which ethnographic principles can be used effectively. They described an educational program in which occupational therapists used four key ethnographic principles to understand family caregivers' perspectives: (a) identify an informant in the home, (b) use an emic approach, (c) engage in self-reflection, and (d) develop a framework for interpreting information. By applying these principles, occupational therapists learned to collaborate with caregivers to develop interventions that fit within the family system of values and beliefs.

In addition to factors that support performance of educator roles in the community, factors that limit the per- 
formance of educational roles include the perception of one's professional roles and definitions of "real practice" in the cultural world in which intervention is typically provided (Lawlor \& Mattingly, 1998). For example, occupational therapists who work in settings that focus solely on providing care to patients may not view caregiver education as legitimate practice. Studying the experiences of occupational therapists who have provided support and education for caregivers in the community may help to better understand the essential skills, knowledge, and attitudes required to perform such services. Such a sample of occupational therapists was available for study. They had been part of a larger study funded by the National Institute on Aging (NIA) that evaluated the feasibility of providing five home sessions of occupational therapy for 202 caregivers of persons with dementia of the Alzheimer's type (DAT). This study has been described elsewhere (Gitlin \& Corcoran, 1996; Gitlin et al., 1999). The collaborative approach used in the larger study was based on the four ethnographic principles described by Gitlin, et al. (1995) and involved helping the caregivers develop strategies to manage the daily care of persons with DAT in their home.

The current study explored the occupational therapists' perceptions of their work in providing support and education for the caregivers and their insights for community practice. The research questions were: How did therapists who collaborated with caregivers to provide support and education in the community view their roles? How did their practice in this new role differ from their customary practice? What insights from their work did the occupational therapists believe could benefit other occupational therapists in clinical practice?

\section{Method}

The pilot study used qualitative methodology and involved four of the nine occupational therapists who had participated as interventionists in the larger study. All four participants had baccalaureate degrees in occupational therapy and worked concurrently as occupational therapists in other clinical settings. Two participants worked in hospitals, one worked in an outpatient rehabilitation center, and one worked in an extended care facility. Participants' levels of clinical experience ranged from 7 years to 18 years.

\section{Data Collection}

Data were collected via interviews. Participants were initially interviewed in person for approximately $1 \mathrm{hr}$ to elicit descriptions of their work with caregivers and to discuss contrasts between this role and their customary role. Participants were also asked to share insights from their work with caregivers that they believed would benefit other occupational therapists.

All initial interviews were audiotaped and transcribed verbatim. The interviews were then entered into qualitative research software (QSR NUD*IST, Version 3.0, 1995) as documents that were coded and analyzed. To support trustworthiness of findings (Lincoln \& Guba, 1985), work sheets detailing tentative themes derived from the initial interviews were mailed to participants 6 months after the first interview. Follow-up telephone interviews lasting 20 min to $30 \mathrm{~min}$ were conducted with all participants approximately 10 days after the work sheets were mailed. These follow-up interviews served as a means of member checking in which participants commented on the accuracy and comprehensiveness of the themes. Revisions to themes based on participants' comments were made during the follow-up interview. An additional means of ensuring credibility of study findings was the participants' review of an early draft of the present article.

\section{Data Analysis}

Primary data analysis methods consisted of concept maps (Miles \& Huberman, 1994), researcher memoing (Strauss \& Corbin, 1990), and vignettes (Miles \& Huberman, 1994). After the first interview, contact summary sheets (Miles \& Huberman, 1994) were developed to assist preliminary analysis (see Figure 1). The broad framework of the interview schedule (description of role, contrasts, impact, recommendations) provided a starting point from which themes were further developed. An initial concept map was developed to represent the themes from participants' interviews, then further elaborated using the display matrixes of QSR NUD*IST. The concept maps and software matrixes enabled sorting of the data and provided a structure that allowed visual representation of relationships between the themes. More detailed concept maps were then developed in response to substantive changes in the categories. For example, an early concept map showed only one category of impact on participants related to their participation in the funded study. However, subsequent analysis revealed two distinct categories of impact: professional impact and personal impact. This change was reflected in later concept maps. The final concept map representing the end-stage of coding and analysis is illustrated in Figure 2.

\section{Results}

\section{Contrasts Between Customary and Collaborative Roles}

Participants discussed four themes reflecting contrast between their typical clinical practice and their intervention in the NIA study: setting, timeline, intervention focus, and interactions.

Setting. A key contrast between the participants' typical practice contexts and their intervention in the study was providing intervention in the home. Participants reported that collaboration was a necessity because they were working with the caregivers in their homes, the caregivers' domain. Participants also believed that the home setting more clearly 

Contact type-Visit
Location-Participant \#3's Workplace
Main issues
- Strong need for caregivers to recognize that they do not have to do everything themselves; they can and should take "time out" as well as learn to use available community and family resources.
- Unique role of occupational therapy in analyzing activities and determining solutions to problems in daily living
Information obtained or not obtained on target questions
Perceptions of collaborative roles
Contrast with typical roles
Helping and limiting factors in collaborative practice
Ways to transform occupational practice
- Helping caregiver (especially men) see that it is ok to use outside resources
- Really understanding what caregivers go through - the nuts and bolts of their day-to-day existence
- Takes place in home where there is a structure already in place versus the occupational therapist establishing the structure
- Occupational therapist needs to listen more to caregiver
- Similar to typical role in problem-solving aspect
- Really listening and showing caregiver a specific strategy or doing it for them initially if they do not understand
- Need to gain a deeper understanding of families' values and lifestyles
- Need to be aware of tremendous changes that families undergo when caring for a person with dementia of the Alzheimer's type
- Unique role of occupational therapy in analyzing activities and determining appropriate intervention
- Need to recognize that you do not have to have all the answers but can problem solve with the caregiver
- Be prepared to expect the unexpected

Other salient, interesting, illuminating, or important aspects of this contact

Many clear examples of caregivers' problems and "stuck" points; helpful for considering collaborative problem solving to see whether this fits into an existing model of problem solving.

Literature to investigate

Literature on problem solving, particularly within a complex context.

Figure 1. Contact summary form for therapists.

focused their attention on caregivers' immediate needs and helped them to better understand the caregiving situation.

Timeline. The fixed 5-visit timeline was also a contrast to usual practice and was viewed as a constraint or helping factor, depending on the participant's typical role. For example, the participant who worked concurrently in long-term care viewed the five visits as a constraint, whereas a participant whose usual practice was acute care saw the five visits as a luxury.

Intervention focus. Focusing intervention on the caregiver was a notable contrast from the occupational therapists' customary practice. Participants considered the intervention focus on the caregiver important for two reasons: (a) They saw caregivers as a neglected population who had a strong need for intervention, and (b) caregivers had already faced very difficult situations over time. The caregivers' extensive experience in addressing difficult caregiving issues often required the occupational therapists to go beyond simple solutions because caregivers had already tried and rejected many interventions on their own.

Interactions. Participants emphasized five interrelated aspects of interaction in their collaboration with caregivers: (a) listening, (b) viewing the caregiver as the expert or "lay practitioner" (Hasselkus, 1988), (c) validating the caregivers' efforts, (d) helping the caregiver to transfer existing strategies to other problem areas, and (e) "reframing" (Schön, 1987) the caregiving situation.

An intensive form of listening was considered essential to successful intervention. As one participant stated: "You really had to listen to what they were saying, or in the end, nothing you did made any difference." This type of listening went beyond attentiveness or use of active listening strategies, such as restatement and clarification (Davis, 1998). Instead, this form of listening was described as qualitatively different than customary modes of listening. Viewing the caregiver as the expert on the daily care of their family members made the listening process different. The occupational therapist became a collaborator in the caregiver's own problem-solving efforts instead of an expert prescribing a solution. However, caregivers sometimes needed help in seeing themselves as experts. Validating the caregivers' strategies became an important intervention strategy. In many cases, the caregiver had initiated effective strategies but did not recognize their importance. For example, one caregiver's spouse could not dress independently because this activity was too complex. By spontaneously setting out his clothes on the bed in an organized way before telling him to get dressed, she set up a context of cues that facilitated his independent dressing. However, the caregiver did not recognize this as an effective strategy until the occupational therapist pointed it out. Recognizing the effectiveness of their own strategies confirmed the caregivers' efficacy and enabled them to transfer strategies to other situations.

Reframing the caregiving situation was another strategy that the participants implemented frequently. They viewed caregivers' beliefs about their caregiving role as a 


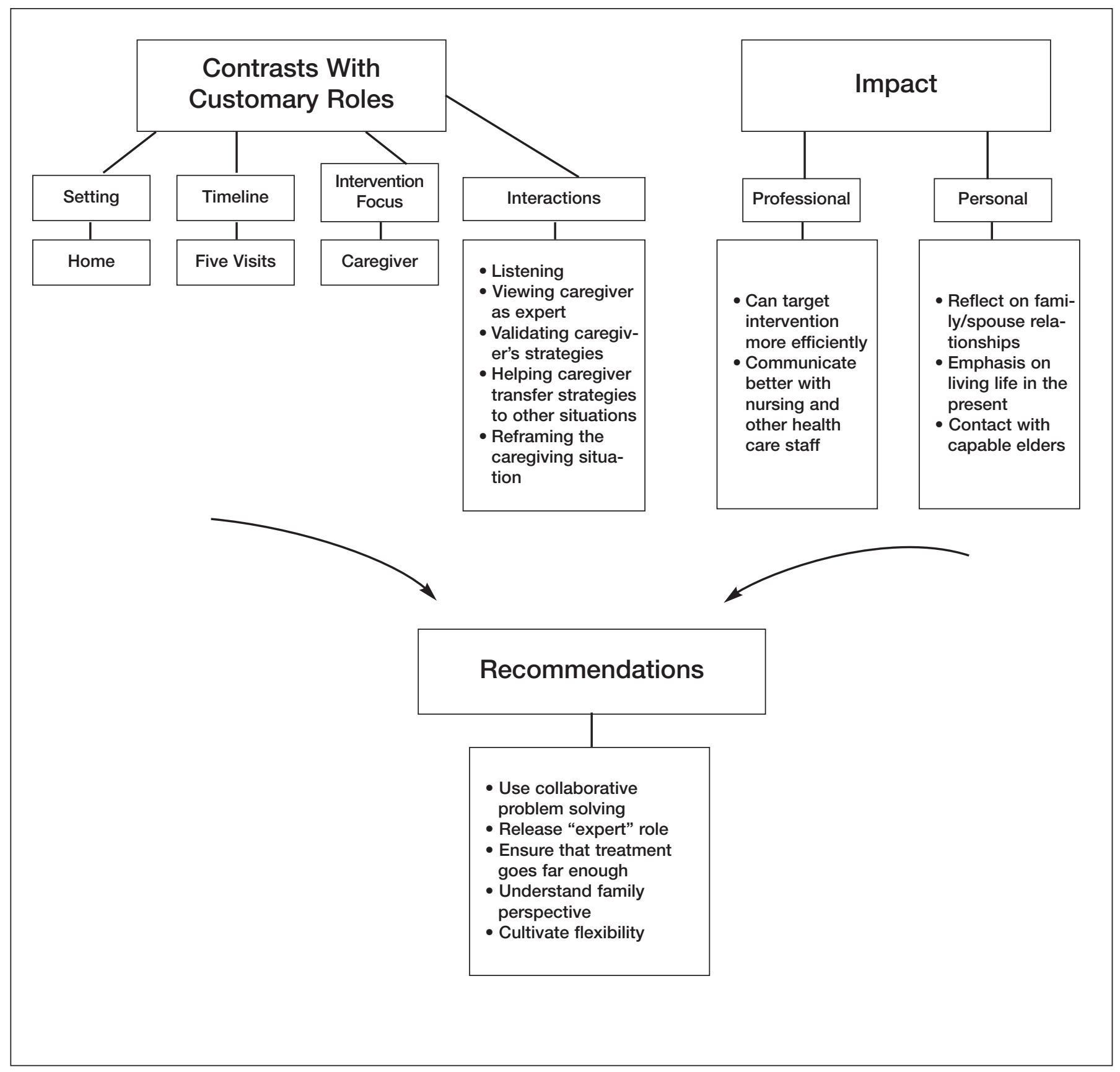

Figure 2. Final concept map.

major block in many instances, so they believed that it was important to help caregivers see their roles differently. For example, many caregivers refused to take "time out" from the caregiving role and believed they had to handle all the caregiving responsibilities themselves. Helping caregivers see the caregiving situation in a different way (reframing) usually included three components: (a) showing caregivers that it was permissible, even desirable to take time for themselves, (b) enabling caregivers to release expectations of themselves and their family member with DAT that no longer produced positive results, and (c) showing caregivers a different standard by which to judge the effectiveness of their strategies.

Reframing caregivers' views toward taking time for themselves was encouraged by connecting caregivers with support systems such as Alzheimer's and church support groups. By doing this, the participants conveyed the message, "This is okay. You don't have to be here 24 hrs a day." Sometimes, caregivers countered this suggestion by stating that they disliked asking anyone for help, which presented an opportunity for further reframing. For example, one participant responded: "You know how good it feels for you to help somebody. Allow someone else to have that feeling. You're not burdening this responsibility on someone when you go to a support group or go food shopping. You're allowing that person to help you."

Caregivers also had many expectations of their family members with DAT that seemed to interfere with their ability to develop solutions for daily problems. For example, some caregivers expected the family member with DAT to 
continue to meet customary social standards, such as daily bathing or weekly church attendance. However, the care recipients often fought the caregivers' attempts to make them meet these standards. The participants found that caregivers could manage their caregiving tasks if they were taught how to reexamine their social standards and personal values. This was important because caregivers often continued to ascribe to standards and values that had negative effects on them and on the care recipient.

Another component of reframing was to help caregivers to release expectations of what they considered proper and socially acceptable in their own behavior. For example, the participants explained to caregivers that it may not be desirable to tell the truth to persons with DAT if it produces agitation (Mace, 1991). They also showed caregivers that it is acceptable to feel angry at the family member's behavior or to consider nursing home placement. Additionally, the participants pointed out that it is permissible, and even desirable, for caregivers to fulfill their own needs. They reported that caregivers were often frustrated when the family member did not respond to the strategies they used. They thought that the standards by which caregivers judged the effectiveness of their caregiving were often too high. Thus, intervention was also directed toward helping caregivers reframe their beliefs about what constituted success. One participant used the following example: "When he is incontinent only once a day instead of four times a day, that's progress." Seeing the small successes as successes and not failures was an important intervention strategy for these caregivers.

\section{Professional and Personal Impact}

Working on the NIA study had an impact on participants' clinical practice and personal lives. Participants reported that they were better able to target the needs of patients and families and became efficient in performing this function.

Another impact of this experience was the participants' improved ability to work with other health care staff members, particularly nurses and nursing assistants. One participant stated:

\footnotetext{
It helped me to communicate and collaborate with other people that I work with [in a nursing home]. The effectiveness of a lot of things that I do depends entirely on nursing carrying it out. And I really have to see their perspective. [I arrange] my splint schedules... around the nursing schedule. There are certain times that it's not good to be putting [the splints] on or taking them off. So I really have to see the nurses' [perspective], just like I had to see the caregivers'.
}

The personal impact of working with caregivers included appreciating the spousal relationships of older adults; valuing life in the present; interacting with many older adults who were highly competent, intelligent, and independent; and seeing the caregivers' devotion to their family members:

You would go [into the home], and there was the person with Alzheimer's, curled up in a fetal position and needing to be tube-fed...and the caregiv- er was there taking care of him. It was absolutely amazing what they did.

\section{Participants' Recommendations}

The participants had five interrelated recommendations for other occupational therapists: (a) use and further develop the skill of collaborative problem solving; (b) realize that you do not always have to be the expert; (c) ensure that treatment goes far enough; (d) understand the family's values and experience of caregiving; and (e) cultivate flexibility.

Participants saw collaborative problem solving as a skill that strongly affected their practice long after their experience in the larger study ended. A key element of the ability to collaborate with others and arrive at a joint solution was to recognize that the occupational therapist does not always have to be the expert. This included willingness to release the expert role and openness toward others' contributions:

You have to really be open to what the families and patients can teach you. So it's okay not to know all the answers. You need to know where to find the answers, work with the [patient] to find the answers... know where to get supervision. But you don't have to go in with all the answers.

Releasing the expert role benefited participants' relationships with other health care staff members as well as patients and families. In particular, they noted the value of working collaboratively with aides and nursing staff to develop solutions for problems in patient care. These solutions included safe transfer techniques and effective carryover for daily tasks. This was similar to their collaborative work with caregivers; aides and nursing staff frequently initiated solutions to problems but did not always recognize the effectiveness of their solutions.

Working in the home over an extended period made the participants conscious of the many needs and challenges that caregivers and persons with DAT face. (The five visits were typically conducted over 4 to 6 weeks.) They became acutely aware that the view of patients previously available in their customary practice contexts represented "the tip of the iceberg" and might not even represent the person's actual situation at home. For example, one participant reported that it would be valuable to spend an entire day with a patient to see his or her whole routine instead of focusing on smaller chunks of daily activity: "What little bit we see in rehab may indicate that a client gets tired walking across the gym floor. But we don't really know if the client can get from here to the bathroom."

Ensuring that treatment goes far enough also meant collaborating with caregivers to develop their own strategies to meet the challenges of caring for their family member. Ideally, the caregiver could then apply these strategies to similar situations. One participant described a caregiver who she believed received optimum benefit from the intervention because she generalized the skills she had learned from the occupational therapist: "She was able to take 
those skills and apply them to the next problem that came up, it wasn't just isolated things she was learning." For example, this caregiver could use the activity simplification skills that the occupational therapist taught her to use for dressing activities and apply them to feeding activities. The participant further explained that this caregiver telephoned long afterward to thank her, stating that she had been able to keep her husband at home until he died, which may have been partly because of the educational process she had gone through with the occupational therapist.

The participants also believed that intervention with caregivers cannot be effective unless the occupational therapist can work within the family's system of beliefs and values. This includes the ability to respect a family's values and beliefs and to understand the overall meaning of caregiving for that particular family (Hasselkus, 1989, 1994).

Participants noted the importance of the home environment in providing clues to the family's perspective on caregiving. They commented that some homes almost looked like skilled nursing facilities with a hospital bed and other medical equipment, whereas others showed no obvious signs that a person with DAT lived there. Family values and the importance of maintaining a sense of normalcy were reasons attributed to the latter home environment.

Participants had differing views about whether the flexibility required for occupational therapy practice is a skill that can be developed or an innate quality. However, all participants agreed with the recommendation, "don't set things in your mind," regardless of their views about the origin of this quality.

\section{Discussion}

This pilot study raises questions about the ways in which practice contexts influence delivery of occupational therapy services. Findings support Schell and Cervero's (1993) assertion that personal and practice contexts are critical aspects of clinical reasoning and can change enactment of occupational therapist roles.

Working in caregivers' homes and focusing intervention on the caregiver appeared to create a practice context that required collaboration in order to make intervention effective. Participants had little or no experience working in patients' homes before their involvement with the NIA grant. Instead, they practiced in settings such as hospitals and rehabilitation centers where the primary focus is on the patient and where the home influence on individuals and families is less immediate. As Rogers (1983) pointed out, institutional settings can foster vague, "clinic-bound" perceptions that underestimate the influences of the home environment on the person's functioning.

The 5-visit timeline also influenced the practice context. The participants may have been better able to focus their intervention given an adequate but not excessive period in which to understand caregivers' perspectives and tar- get intervention. Overall, the participants saw this timeline as an optimal balance between comprehensiveness and efficiency-a balance also valued by consumers of occupational therapy and by third-party payers (Foto, 1997).

The intervention protocols also directed the participants to use an ethnographic approach, to jointly determine priority areas for intervention with caregivers, and to work collaboratively to achieve the caregivers' desired outcomes. Thus, the protocols appeared to foster the interactions that contrasted with participants' customary practice: intensive listening, viewing the caregiver as the expert, validating the caregivers' efforts, helping the caregiver to transfer existing strategies to other problem areas, and reframing the caregiving situation. In summary, the participants, like the caregivers they treated, learned new skills and new ways of conceptualizing their roles.

As Lawlor and Mattingly (1998) asserted, further research is needed to develop adequate models that reveal the complexities of practice and the ways in which contextual features can influence clinical reasoning and intervention. This is critical because effective clinical reasoning highly depends on the therapist being able to "read the context" (Mattingly, 1991, p. 985). Unless the specific influences of practice contexts are known, their features cannot be fully analyzed or used to better understand and improve practice. New methods for examining practice may be needed so that the many aspects of practice can be fully explored. Such methods may include a focus on the systems in which occupational therapists practice instead of focusing solely on the reasoning processes of individual clinicians as the unit of analysis. Because mental activity highly depends on the context in which it occurs, this is a logical way to approach clinical reasoning (Brown, Collins, \& Duguid, 1989; Cole \& Engeström, 1991; Greeno, 1997; Lave, 1988). Additionally, a distorted view of individual mental functioning can result from inattention to the overall system in which cognitive activity occurs (Hutchins, 1993).

Cultural historical activity theory (Cole \& Engeström, 1991; Engeström, 1993; Leont'ev, 1978) may provide a useful framework for analyses of clinical reasoning within specific practice contexts. This theory proposes that context is neither a "container" nor solely an experience created by persons in interaction but by the simultaneous influence of many aspects. Analyzing these multiple influences may provide a more comprehensive view of occupational therapy practice and better reflect the richness and complexity of clinical reasoning.

\section{Limitations}

As a pilot study that explored the role perceptions of four occupational therapists working within a specific practice context, findings may not be transferable to other occupational therapists in community settings. Other factors that could have influenced the participants' perceptions of their roles and their collaborative skills include educational 
preparation, experience in particular settings that emphasized collaboration, and length of time in clinical practice.

\section{Conclusion}

Participants' recommendations for change in occupational therapy practice emphasize the shift from a prescriptive approach to a collaborative approach, acknowledgment of others as experts, inclusion of family perspectives, and greater attention to the needs of patients and families in their home environments. This change in practice approach represented a major shift in focus by all the participants, despite that they were experienced therapists who had been specifically trained to use a collaborative approach. The difficulty in making this shift may be related to the participants' customary perceptions, beliefs, and practices of their roles within institutional and cultural structures in health care (Lawlor \& Mattingly, 1998). Thus, considerable change in thinking and delivering intervention may be required by experienced as well as by novice therapists as they transition from traditional practice contexts to contexts that require different approaches. Comprehensive training programs that address occupational therapists' attitudes and beliefs in addition to knowledge and skills may be necessary to facilitate such transitions.

\section{Acknowledgments}

I thank the study participants; Laura N. Gitlin, PhD; and Mary A. Corcoran, PhD, OTR/L, FAOTA. The research reported in this article was generated from a study funded by the National Institute on Aging, RO1-AG-10947, for which Dr. Gitlin was principal investigator and Dr. Corcoran was co-investigator. The views contained in the article reflect those of the author.

\section{References}

Baum, C., \& Law, M. (1998). Nationally Speaking-Community health: A responsibility, an opportunity, and a fit for occupational therapy. American Journal of Occupational Therapy, 52, 7-10.

Brown, J. S., Collins, A., \& Duguid, P. (1989). Situated cognition and the culture of learning. Educational Researcher, 18, 32-42.

Cole, M., \& Engeström, Y. (1991). A cultural-historical approach to distributed cognition. In G. Salomon (Ed.), Distributed cognitions: Psychological and educational considerations (pp. 1-46). New York: Cambridge University Press.

Davis, C. M. (1998). Patient practitioner interaction. Thorofare, NJ: Slack.

Devereaux, E. B. (1991). The Issue Is-Community-based practice. American Journal of Occupational Therapy, 45, 944-946.

Engeström, Y. (1993). Work as a testbench of activity theory. In S. Chaiklin \& J. Lave (Eds.), Understanding practice (pp. 64-103). New York: Cambridge University Press.

Foto, M. (1997). Preparing occupational therapists for the year 2000: The impact of managed care on education and training. American Journal of Occupational Therapy, 51, 88-90.
Gitlin, L. N., \& Corcoran, M. C. (1996). Managing dementia at home: The role of home environmental modifications. Topics in Geriatric Rehabilitation, 12(2), 28-39.

Gitlin, L. N., Corcoran, M. C., \& Leinmiller-Eckhardt, S. (1995). Understanding the family perspective: An ethnographic framework for providing occupational therapy in the home. American Journal of Occupational Therapy, 49, 802-809.

Gitlin, L. G., Corcoran, M., Winter, L., Boyce, A., \& Marcus, S. (1999). Predicting participation and adherence to a home evironmental intervention among family caregivers of persons with dementia. Family Relations, 48, 363-372.

Greeno, J. G. (1997). On claims that answer the wrong question. Educational Researcher, 26, 5-17.

Hasselkus, B. R. (1988). Meaning in family caregiving: Perspectives on caregiver/professional relationships. Gerontologist, 28, 686-691.

Hasselkus, B. R. (1989). The meaning of daily activity in family caregiving for the elderly. American Journal of Occupational Therapy, 43, 649-656.

Hasselkus, B. R. (1994). Professionals and informal caregivers: The therapeutic alliance. In B. R. Bonder \& M. B. Wagner (Eds.), Functional performance of older adults (pp. 340-351). Philadelphia: F. A. Davis.

Hutchins, E. (1993). Learning to navigate. In S. Chaiklin \& J. Lave (Eds.), Understanding practice (pp. 35-63). New York: Cambridge University Press.

Lave, J. (1988). Cognition in practice. New York: Cambridge University Press.

Lawlor, M. C., \& Mattingly, C. E. (1998). The complexities embedded in family-centered care. American Journal of Occupational Therapy, 52, 259-267.

Leont'ev, A. N. (1978). Activity, consciousness, and personality. Englewood Cliffs, NJ: Prentice Hall.

Lincoln, Y. S., \& Guba, E. G. (1985). Naturalistic inquiry. Newbury Park, CA: Sage.

Mace, N. L. (1991). The 36-hour day: A family guide to caring for persons with Alzheimer's disease, related dementing illnesses, and memory loss in later life. Baltimore: Johns Hopkins University Press.

Mattingly, C. (1991). What is clinical reasoning? American Journal of Occupational Therapy, 45, 979-987.

McCall, M. (1998). What do we need to know to practice occupational therapy in the community? American Journal of Occupational Therapy, 52, 11-18.

Miles, M. B., \& Huberman, A. M. (1994). Qualitative data analysis. Thousand Oaks, CA: Sage.

QSR NUD*IST 3.0 [Computer Software]. (1995). Melbourne, Australia: Qualitative Solutions and Research.

Rogers, J. C. (1983). Clinical reasoning: The ethics, science, and art, 1983 Eleanor Clarke Slagle lecture. American Journal of Occupational Therapy, 37, 601-617.

Schell, B. A., \& Cervero, R. M. (1993). Clinical reasoning in occupational therapy: An integrative review. American Journal of Occupational Therapy, 47, 605-610.

Schön, D. A. (1987). Educating the reflective practitioner. San Francisco: Jossey-Bass.

Strauss, A., \& Corbin, J. (1990). Basics of qualitative research. Newbury Park, CA: Sage. 